\title{
A Lei Maria da Penha e os atendimentos multidisciplinares: os sentidos de uma proposta diferente no Fórum do Núcleo Bandeirante, Distrito Federal ${ }^{1}$
}

\author{
Ranna Mirthes Sousa Correa \\ Universidade de Brasilia, Brasilia, Brasil
}

DOI: 10.11606/issn.2316-9133.v22i22p238-249

resumo $\mathrm{O}$ presente artigo tem o objetivo de analisar o tratamento dado aos casos no Fórum do Núcleo Bandeirante, no Distrito Federal, que utiliza um modelo diferente de primeiro atendimento às partes, a partir da utilização de uma equipe multidisciplinar composta por profissionais de Direito, Psicologia e Assistência Social. Destaca-se a tentativa de entender quais são os diferentes sentidos assumidos pelos atendimentos, seja judicial ou terapêutico, e que elementos operam na construção e transformação desses sentidos no decorrer do processo na justiça, em busca de efetiva resoluçâo do conflito. A presença dos psicólogos e assistentes sociais abre um espaço de enunciação mais claro e aberto sobre as situaçôes que envolvem o conflito, funcionando com uma finalidade terapêutica, trazendo à tona elementos capazes de ajudar na resolução do conflito em sua origem.

palavras-chave Lei Maria da Penha; Equipe multidisciplinar; Judicialização; Violência doméstica; Gênero

The Maria da Penha's law and the multidisciplinary care: the senses of a different proposal at Núcleo Bandeirante's Court, in Distrito Federal.

abstract This article aims to analize the treatment given to the court cases in Núcleo Bandeirante, which uses a different approach to the first treat- ment to suitor from the use of an multidisciplinary team composed by lawyers, psychologists and social assistants. It emphasis the attempt to understand which are the different meanings assumed by the treatment - judicial or therapeutic -, and which elements are operating in the construction and transformation during their case in the court, pursuing the conflict resolution. The presence of psychologists and social assistance workers opens a clear space about the conflict situations involving, acting as a therapy and also, bringing out all the elements capable to aid in the conflict resolution. keywords Maria da Penha's Law; Multidisciplinary team; Judicialization; Domestic violence; Gender.

\section{Introduçáo}

A partir da aprovação da Lei 11.340/06, o sistema jurídico brasileiro alterou a forma de tratamento aos casos de violência doméstica contra a mulher no país. A nova Lei tem como objetivo tratar das relaçóes que durante muito tempo foram consideradas fora do espaço regulatório do Estado, com o objetivo de erradicar e punir as diversas formas de violência existentes contra a mulher. Dessa maneira, foi retirada dos Jecrim a competência para julgar tais casos, e a criação dos Juizados de Violência Doméstica e Familiar contra a Mulher contribuiu para o agravamento do tratamento dado ao opressor, assim como estabelecer me- 
didas de assistência e proteção às mulheres em situação de violência.

A respeito da trajetória histórica da criação da Lei popularmente conhecida como Maria da Penha, e as diversas outras medidas implantadas anteriormente pelo Estado brasileiro, como a criação das Deam's e Jecrim's, na tentativa de coibir tais tipos de violência, a lei 11.340/06 determina a criação de Juizados de Violência Doméstica com o objetivo de atuarem na defesa dos direitos das mulheres. A questão que merece atenção é justamente verificar como, a partir da criminalização da violência de gênero no Brasil, está sendo a atuaçáo e o desempenho desses juizados no que se refere à ampla defesa dos direitos das mulheres vítimas de violência, seja ela física, sexual, patrimonial, psicológica e moral.

Essa breve exposição tem como objetivo principal analisar o tratamento judicial dado aos casos de violência doméstica em Juizados do Distrito Federal. No ano de 2012, o foco da pesquisa foi no $1^{\circ}$ Juizado de Violência Doméstica e Familiar contra a Mulher do Núcleo Bandeirante, que utiliza um modelo diferente de primeiro atendimento às partes, partir da utilização de uma equipe multidisciplinar composta por profissionais entre as áreas de Direito, Psicologia e Assistência social.

Para a realização da pesquisa, foi necessário o acompanhamento dos atendimentos de Dezembro de 2011 a Agosto de 2012. Os acompanhamentos foram realizados por meio da observação participante nas salas de atendimento, com o intuito de observar os procedimentos da equipe, assim como a postura dos litigantes. Concomitante às observaçóes dos atendimentos, foram realizadas pesquisas aos processos para um acompanhamento mais detalhado do processo, além da seleção de 23 casos com o intuito de identificar elementos comuns que suscitassem uma discussão mais aprofundada sobre a dinâmica desenvolvida pela equipe nos atendimentos, assim como os sentidos que possam assumir durante a trajetória do processo na Justiça.

A iniciativa do Juizado em fazer um atendimento especializado feito por uma equipe multidisciplinar como forma de primeiro acesso à Justiça, desperta atenção no que se refere à forma como este trabalho será desenvolvido e sua relevância para a resolução do conflito em sua origem. Mesmo não funcionando como uma mediação propriamente dita, o atendimento aponta consideraçóes importantes, como uma medida que visa administrar o conflito, aumentando o espaço de enunciação das versôes das partes envolvidas, oscilando como um espaço ora jurídico ora terapêutico, marcado pela presença da parceria de psicólogos e advogados.

Destaca-se, neste paper, a tentativa de entender quais são os diferentes sentidos assumidos pelos atendimentos, seja mais judicial ou terapêutico, e quais elementos operam na construção e transformação desses sentidos no decorrer do processo na justiça.

\section{A Lei 11.340/06 e a judicializaçáo dos conflitos}

A partir da criação das DEAMS, dos JECRIMs e do advento da lei 11.340/06, a violência contra a mulher passou a ser tratada com mais atenção no âmbito jurídico brasileiro. A Lei Maria da Penha representa um marco na efetivação da política para as mulheres no Brasil a partir do reconhecimento da violência contras as mulheres como um problema social no Brasil.

Em um trabalho referente às novas medidas adotadas pela Lei $11.340 / 06$, Pasinato afirma que as medidas previstas na Lei Maria da Penha podem ser organizadas em três eixos de intervenção: o primeiro eixo diz respeito às medidas cri- 
minais para a punição da violência, assim como a adoção de procedimentos como a retomada do inquérito policial, a prisão em flagrante, preventiva ou decorrente de pena condenatória, "a restrição para determinação criminal para determinados crimes e o veto para aplicação da lei 9099/95 a qualquer crime que se configure como violência doméstica" (PASINATO, 2010, p.220221). No segundo eixo encontra-se um conjunto de medidas protetivas, com caráter de urgência para a mulher, aliado a medidas que se voltam ao seu agressor, integrando, nesse, eixo medidas de assistência que contemplem o atendimento psicológico, jurídico e social. E, no terceiro eixo, "estão as medidas de prevenção e de educação, compreendidas como estratégias possíveis e necessárias para coibir a reprodução social da violência, e da discriminação baseadas no gênero" (PASINATO, 2010, p. 220-221).

A autora ainda aponta que a articulação desses três eixos depende da criação dos Juizados de Violência Doméstica e Familiar contra a Mulher, que aspiram garantir a operacionalização de forma integrada das medidas previstas na lei, proporcionando às mulheres maior acesso aos seus direitos e autonomia para se livrarem da condição de violência a que estão sendo submetidas. Pasinato ainda completa:

Mas não é apenas o judiciário que precisa se reorganizar para a aplicação da lei. A correta implementação da lei exige a formulaçẫo de políticas públicas de gênero direcionadas a integração entre a polícia, o judiciário e dos diferentes serviços nas áreas de segurança, saúde, assistência jurídicas, médica e psicológica, entre outras, que prestam atendimento às mulheres em situação de violência (PASINATO, 2010, p. 220-221).

Contudo, é importante considerar que a lei, desde a sua criação, vem enfrentando e ainda enfrenta muitas dificuldades para a sua fiel apli- cação, configurando uma relevante discussão para a forma com que essa judicialização vem sendo feita e qual o verdadeiro impacto disso na efetiva resolução de conflitos. Azevedo tece pertinentes consideraçóes sobre o processo da elaboração da lei 11.340 e seu impacto na realidade jurídica brasileira, ao dizer:

$\mathrm{O}$ que se quer aqui destacar é que o processo de elaboraçáa da Lei 11.340/06 náo incorporou o debate mais recente sobre os mecanismos necessários para a elaboração, implantação e monitoramento dos novos procedimentos judiciais, na linha de uma Sociologia Jurídico-Penal, muito menos o legado da Criminologia Crítica no tocante aos problemas advindos da adesão à alternativa punitiva como soluçáo de problemas sociais (AZEVEDO, 2008, p.129-130).

A discussão de alguns autores sobre a criminalização da violência doméstica a partir da promulgação da Lei Maria da Penha ainda suscita debate no que se refere à utilização de medidas mais sensatas para se fazer cessar as agressóes. Maria Stella Amorim ainda lembra que:

(...) embora festejada por todos, inclusive pelos autores aqui citados e que não lhe pouparam observaçôes, a operacionalização e a eficácia da Lei Maria da Penha pode sofrer da mesma fragilidade institucional que os JECrim. Se este despenalizava, a Lei Maria da Penha penaliza a violência contra a mulher. Se o JECrim falhou, por falta de políticas auxiliares no combate desta violência grave e ainda bastante arraigada nas sociedades atuais, inclusive na brasileira, a Lei 11.340/06 amparou-se em rede de proteção do Judiciário, do Ministério Público, da Defensoria Pública, dos Executivos Federais, Estaduais e Municipais, de equipes multidisciplinares e de organizaçôes não-governamentais. Mas, estará esse extenso manto protetor suficientemente articulado para 
A Lei Maria da Penha e os atendimentos multidisciplinares $\mid$ 24I

conceder proteção à mulher vítima da violência doméstica e familiar? (AMORIM, 2008, p.15)

É pertinente acrescentar a discussão proposta por Kant de Lima (2009) sobre o direito, na qual afirma que o direito é como uma parte normativa da sociedade ou um "modo de vida" normativo (p. 30). Regina Lúcia Teixeira Mendes também contribui para a discussão de conflito, ou seja, o Estado surge não como administrador de conflitos, mas como pacificador social e fator de equilíbrio entre as desigualdades irredutíveis existentes entre os segmentos da sociedade. Completa ainda que:

\section{A desigualdade jurídica é entendida, equivoca- damente como sinônimo de dessemelhanças, di- ferenças, ou ainda, como instrumento legítimo para compensar a desigualdade de fato. Nesse caso, a administração de conflitos se traduz na repressão deles ou numa conciliação forçada, que visa a sua extinção ( MENDES,2005, p. 26-27).}

Levando em consideração os dilemas da judicialização e as dificuldades de operacionalização do direito, é válido pensar que no direito brasileiro, o processo não se volta para consensualizar os fatos e nem para estabelecer o que ficou provado ou não. Pelo contrário, através da lógica do contraditório, que veda qualquer consenso entre as partes, os fatos e as provas são determinados pela autoridade interpretativa do Juiz (KANT DE LIMA, 2009, p. 31). É válido analisar como consequência da judicialização que os conceitos que se baseiam nas formas de convencimento mostram-se inadequados para analisar o que ocorre no mundo do direito brasileiro, pois estão fundados na prévia e na suposta igualdade dos interlocutores. $\mathrm{O}$ autor ainda aponta que "dada essa desigualdade legal explícita entre os interlocutores, é o argumento de autoridade que prevalece na administração de conflitos e náo a autoridade do argumento das partes envolvidas" (KANT DE LIMA, 2009, p.31). Por essa razão, a mulher, muitas vezes como a única testemunha do próprio caso, tem a legitimidade do seu argumento colocada à prova pelo fato do juiz, como único conhecedor de um saber particularizado e portador de uma autoridade quase que inquestionável, decidir sua sentença baseado em seu sentir jurídico e nas suas impressóes sobre os fatos narrados. Essa é uma questão que merece atenção para pensar sob quais lógicas o judiciário opera na tentativa de resolução de conflitos, levando em consideração a versão dos fatos citados pelas partes, assim como o que estas esperam alcançar com o andamento do conflito até a Justiça.

\section{Uma proposta diferente: a equipe multidisciplinar}

O trabalho desenvolvido no $1^{\circ}$ Juizado de Violência Doméstica e Familiar contra a mulher do Fórum do Núcleo Bandeirante surgiu da implantação de um projeto no final do ano de 2011, intitulado "Projeto Setorial para a Implantação e Desenvolvimento de equipe Multiprofissional no contexto da Violência Doméstica e Familiar", que consiste na realização de atendimentos ministrados por uma equipe multidisciplinar composta por servidores do Fórum, bacharéis em Direito, psicólogos e assistentes sociais, que funcionam como primeiro acesso das partes à Justiça e que antecedem as audiências judiciais. Apesar de a equipe desempenhar atribuiçóes muito similares daquelas desenvolvidas nas audiências preliminares, o objetivo ali proposto é baseado no discurso da criação de um espaço mais amplo de enunciaçáo das partes sobre o conflito, capaz de trazer à tona todos os aspectos que envolvem e deram origem ao conflito. 
242 Ranna Mirthes Sousa Correa

Os atendimentos são feitos em três salas pequenas, dispostas uma ao lado da outra, cada uma com uma mesa redonda no centro, sendo que a parede virada para o corredor tem placas de vidros sendo possível apenas visualizar o que está acontecendo no interior das salas. A principal diferença entre os demais Juizados se refere à ausência dos magistrados na sala, assim como a ausência de advogados, só sendo solicitados em alguns casos específicos, e caso seja necessária a intervenção do Juiz no atendimento, a equipe se desloca até a sala ao lado, ou dependendo do caso, o Juiz se desloca até as salas de atendimento e, por algumas vezes, o atendimento é finalizado pelo juiz na sala de audiências convencionais.

\section{A dinâmica dos atendimentos}

O início dos atendimentos é marcado pelas apresentaçóes das equipes e por uma explicação mais detalhada do trabalho da equipe. A explicação consiste em deixar claro às partes que o trabalho ali desenvolvido apresenta espaço de maior liberdade para contar o que realmente estava acontecendo, sem julgamentos de juízo de valor ou prerrogativas de uma versão certa ou errada sobre os fatos. A preocupação da equipe é latente em esclarecer que o atendimento funciona como um amplo espaço de enunciação das partes, inclusive do ofensor que tem espaço de fala para esclarecer a sua versão dos fatos que deram origem à ocorrência. Ainda no início, a equipe esclarece que apesar de ser um espaço mais amplo para uma conversa, aquele não é ambiente de produção de provas, e sim para tentar resolver, naquele momento, diversos outros aspectos que envolvem o conflito que deu origem ao boletim de ocorrência, como por exemplo, o estabelecimento de pensão, estipular horários de visitas dos filhos, assim como dias e horários. Segue abaixo alguns trechos dos relatos:

C. apresenta a equipe multidisciplinar e explica o propósito da equipe. Fala que não substitui audiência com o Juiz, mas que existe para que as partes tenham oportunidade de falar, para saber o que aconteceu e está acontecendo com as partes, antes da audiência. Diz ainda que as informaçôes que serão ditas ali são sigilosas, e em seguida me apresenta como estudante que está ali para fazer uma pesquisa. (Trecho do relato do processo $\mathrm{n}^{\circ} 22790$ 6/12. Data do atendimento: 07/05/2012).

Em sequência, é feita a oitiva da vítima que começa seu depoimento contando sobre o fato que deu origem ao boletim de ocorrência. Nesse momento, a ofendida tem um espaço de enunciação livre para comentar sobre a atual situação entre o requerido, se aconteceram novos fatos desde o boletim de ocorrência, assim como trazer à tona alguns aspectos que os envolvem e que permeiam o conflito.

Nesse ínterim, é possível perceber as intervençôes dos profissionais do atendimento psicossocial, que utiliza de um parecer técnico, em que o psicólogo poderá fazer leituras do conflito que esclarecerão no calor do momento, como evitar futuros conflitos e desentendimentos. Conforme o relato:

A equipe intervém e diz que é importante preservar a figura do pai e da mãe para as crianças, independentemente do conflito. Dessa forma, ela não deve colocar o pai como se fosse o mal porque apesar de tudo ele continuava sendo o pai (...).

M. propóe então que a medida protetiva de proibição de aproximação seja retirada, pois assim Maria poderia conversar com José sobre os filhos, o que não acontece atualmente. Essa medida seria importante, segundo a psicólo- 
ga, porque a criança se encontra muito dividida e sobrecarregada emocionalmente com o conflito dos pais (...). (Trechos do relato do processo $\mathrm{n}^{\circ} 6846-3 / 11$.Data do atendimento: 12/12/2012).

Após o depoimento da requerente, o próximo passo da equipe é mostrar para a ofendida quais são as opções judiciais as quais têm em relação ao processo que são: o arquivamento do feito, o prosseguimento do feito, ou a suspensão condicional do processo por seis meses. Antes de prosseguir, é importante esclarecer a diferença entre cada uma delas e esperar pela decisão da parte.

A equipe explica para a ofendida que ela tem três opçóes no processo, sendo que é ela quem vai decidir: 1) desistência: "nós não vamos aconselhar a senhora a fazer isso, nós aqui só sugerimos e aconselhamos, não vamos aconselhar a senhora a desistir"; 2) suspensão: o processo vai ficar parado por seis meses pra ver no que vai dar; 3) prosseguimento: 'que eu acho a melhor opçáo para a senhora, nós sugerimos isso, mas é a senhora que vai decidir, mas pela prova documental nós aconselhamos a senhora a não desistir e nem suspender o processo. Desculpa eu falar isso de novo, nosso interesse não é coagi-la, mas é a senhora quem decide'. (Trecho do relato do processo no6405-9/11. Data do atendimento: 21/11/11).

Caso algum membro da equipe ache conveniente, surge a proposta do atendimento psicossocial, um serviço de atendimento às famílias em situação de violência, que seria cinco encontros durantes cinco semanas, um encontro por semana, almejando ajudar as partes a encarar a situação de violência e evitar novas ocorrências, com uma finalidade de trabalho continuado ao que foi iniciado nas salas de atendimento, como segue abaixo:
A equipe pergunta se Marta gostaria de participar das reuniôes do Seravi, que acontecem semanalmente, durante a tarde, por um mês. Diz que lá ela irá encontrar mulheres que passaram pela mesma situação que ela, que poderão ajudá-la e que teria um acompanhamento psicológico participando das reunióes. (Trecho do relato do processo $n^{\circ}$ 0955-5/12. Data do atendimento: 30/04/12).

Em seguida, a requerente se ausenta da sala do atendimento, para que o requerido seja ouvido. É importante frisar que um não toma conhecimento sobre a fala do outro, e só ocupam a mesma sala ao mesmo tempo, se a equipe achar relevante. $\mathrm{O}$ mesmo procedimento é feito com ele, dando espaço para a enunciação da sua versão sobre os fatos, bem como é avisado sobre eventuais decisões a respeito do processo, sobre as sessốes do atendimento psicossocial e todas as informaçôes necessárias. O próximo passo é a atualização dos dados das partes para futuros contatos, como a retificação de número de telefone residencial, celulares e de trabalho, e também o endereço residencial. Depois das partes cientes de todas as decisóes ali tomadas, encerra-se o atendimento. As partes apenas devem esperar alguns minutos no corredor ao lado, para que a equipe possa redigir o termo de atendimento e depois colete suas assinaturas. $\mathrm{O}$ termo de atendimento se assemelha a uma ata de audiência e consta um breve relato sobre o atendimento feito com a ofendida e qual foi a sua decisão sobre o andamento do processo. Ainda consta a decisão proferida pelo Juiz responsável pelo Juizado, bem como sua assinatura.

Antes de prosseguir, apresento a seguir alguns casos provenientes das observaçóes dos atendimentos, para analisar o lugar e a importância dos atendimentos no desenvolvimento do processo na justiça. Para isso, apresento um 
breve relato do caso para em seguida tecer alguns comentários sobre as possíveis análises. Além disso, é válido entender quais fatores são comumentes identificados na observação dos atendimentos como capazes de alternar os sentidos terapêutico e jurídico em que podem vir a assumir.

\section{Caso 1}

A ofendida ainda não havia chegado, e por essa razáo, o atendimento começa com o ofensor. Ele explica que o filho é a sua única preocupação e acredita que a mãe não é uma boa influência para a criança, porque ela não se comporta de uma maneira decente. Afirma que tem condiçóes de criar a criança, ao contrário dela. A equipe decide que antes de prosseguir, é primordial ouvi-la primeiro. A ofendida entra na sala e fica todo o tempo mexendo no celular, náo parecendo dar muita importância. Depois da autorizaçáo da equipe, ela fala que só quer que ele pare de bater nela, já que ele toma remédio controlado e já teve problemas com drogas, além de ser muito ciumento. Ao ser interrogada sobre o que quer com o processo, ela apenas responde que só quer que ele pare de bater nela. A equipe explica sobre as três opçóes, e ela apenas repete que quer que ele pare de bater nela. Insegura, a equipe explica novamente as opçóes sobre o arquivamento, prosseguimento ou a suspensão. A ofendida responde entáo que opta pela suspensão, dizendo que se ele bater nela novamente, ela voltará à delegacia. Nesse momento, a equipe ao avaliar a situação, decide que seria melhor o juiz fazer o atendimento, saindo da sala à sua procura. $\mathrm{O}$ juiz entra trajando a toga, e dá continuidade ao atendimento na mesma sala. O ofensor que parecia tentar se impor perante a equipe, parecia ter se "desar- mado”. Ele diz ao juiz que quer tranquilidade para cuidar do filho e que se não for para ficar junto dela, quer lutar pela guarda da criança. O juiz pede para ele sair da sala para conversar apenas com ela. Pergunta a razáo pela qual ela não quer se separar, e obtém como resposta que não tem condiçóes financeiras para pagar aluguel, e que manda parte do seu salário para sua mãe e suas duas filhas, de outro relacionamento, que moram no Piauí. O juiz pergunta se ela quer tentar mais um pouco para ver se as coisas melhoram daqui para frente. A ofendida comentou que ele a havia proibido de ir ao encontro de casais da Igreja Católica, que era de sua vontade. $\mathrm{O}$ juiz aproveitou esse detalhe para fazer com que ambos participassem desse grupo na Igreja. Ela saiu da sala e o ofensor entrou. $\mathrm{O}$ juiz começou tentando apaziguar os problemas dizendo que ele deveria ir à Igreja também, já que ela não tem família em Brasília, e que seria importante construir uma rede de amigos de bem. Em seguida, o juiz começou a falar para ele não bater mais nela. $\mathrm{A}$ partir desse instante, o juiz ficou mais sério dizendo que ele poderia ser preso por isso e que não admitiria uma nova agressão. A ofendida volta para a sala e o juiz deu um brinquedo de presente para o menino. O juiz constrói um acordo dizendo que ambos deveráo participar do encontro de casais da paróquia, dizendo a ela que deverá pegar o número de telefone da responsável pelo grupo e entregar a ele, porque ele vai pessoalmente ligar para ela para saber se estão cumprindo o combinado.

\section{A presença do juiz no atendimento}

Como relatado acima, nota-se que não estão totalmente claras as razóes pelas quais a equipe considerou importante a presença do juiz no 
atendimento. Apesar do espaço do atendimento ser um espaço mais livre não foi apenas a fala das partes que motivaram a equipe a pedir a presença do magistrado, mas também a postura tanto da requerente quando do requerido no atendimento. A presença do Juiz perante as partes impóe uma legitimidade da justiça e alterou momentaneamente a postura dos litigantes. Atento para o fato de que apesar da presença do juiz ter alterado os rumos do atendimento, este não se transforma em uma audiência nos moldes convencionais. $\mathrm{O}$ fato de ter continuado na sala dos atendimentos, sem a presença de um promotor, as novas características adquiridas pelo atendimento não foram suficientes para atribuir um sentido estritamente judicial ao caso, uma vez que o procedimento utilizado pelo juiz estava nos moldes da proposta feita pelo atendimento, com a preocupação de considerar as reunióes do grupo da igreja como uma boa tentativa que visa dar fim ao conflito.

Apesar de o atendimento demonstrar um resultado semelhante a uma audiência preliminar, colocando em voga os motivos da denúncia, com a oitiva das partes e a decisão dos encaminhamentos judiciais do processo, o atendimento não pode ser considerado como tal, uma vez que, consoante orientação legal, na audiência deverão estar presentes o representante do Ministério Público, o autor do fato e a vítima, e se possível acompanhados por seus advogados.

\section{Caso 2}

Neste tópico, apresento um segundo caso, que diferente do caso anterior, contém elementos terapêuticos que foram fundamentais na mudança do rumo do atendimento feito pela equipe multidisciplinar para uma audiência. $\mathrm{O}$ caso é de um jovem casal, que tem dois filhos e o motivo da briga que deu origem ao conflito foi uma viagem da família que estava marcada para Goiânia, mas em função do atraso do marido, não aconteceu na hora certa. Já de madrugada e alcoolizado, ele quis viajar com filhos e ela negou. Por essa razão, ela conta que foi empurrada e se sente ameaçada por sua agressividade. A descrição do caso é feita a partir do final de sua fala, na primeira parte do atendimento, quando é possível notar elementos significativos para a mudança de rumos do caso.

Segue a descrição do atendimento:

Após contar sobre o fato que deu origem ao boletim de ocorrência, próximo do final de sua fala, depois do comprometimento com o acordo e decidir prosseguir o feito, a ofendida fala sobre um acontecimento que acontecera no dia anterior da audiência. Conta que ele estava bebendo e ao chegar alterado à casa, começaram uma discussão por conta do carregador do celular. Ainda alterado começou a gritar na frente dos filhos e deu um empurrão nela, marcando seu braço. Ao olhar mais atentamente o processo, a equipe percebe que já tem três medidas protetivas deferidas: afastamento do lar, proibição de aproximação e contato com a ofendida. Todos percebem que ele estava descumprindo uma ordem judicial. A equipe percebe que o caso poderia ser mais grave e assume uma postura mais firme ao dizer:

Eu acredito que você já se acostumou com isso, mas a violência não pode mais ser banalizada dessa forma. A senhora está correndo risco em casa, junto com os seus filhos. Ele tem que ser afastado de casa e pagar uma pensão para os seus filhos. Maria, você está vivendo numa situação de risco eminente, não que eu esteja falando que você tenha que se separar, mas você tem que ter consciência do risco que está correndo e que está colocando os seus filhos. (Diário de campo, processo no 585-0/12. Data: 12/04/12). 
Depois de ouvir as consideraçóes da equipe, sentiu-se mais à vontade para contar que costuma ouvi-lo falar que tem uma arma e que anda com ela dentro do carro. Detalha que a filha tem as fotos de uma arma no celular e o pai afirma que é dele. Assim sendo, a equipe sugere que o juiz autorize uma busca e apreensão da arma, bem como o reforço das protetivas, e se necessário, um oficial de justiça para que ela saia de casa. Mais uma vez, a equipe ressalta que a ofendida não estava dando a devida importância à situação e que continuava vendo isso como algo banal. "o que mais estava faltando lhe acontecer para a senhora entender?" perguntou mais uma vez. Enquanto a equipe sai da sala para uma conversa com o juiz, a psicóloga aproveita para ter uma conversa com a ofendida, mas utiliza uma técnica para isso. Ela pede para que a ofendida se sente de frente para ela, e largue a bolsa em cima da mesa, tirando anéis e relógio. Sentada de frente para a ofendida, a psicóloga inclina seu corpo levemente para frente e começa a bater com as duas mãos nas coxas de Janete, como se estivesse batendo um tambor, produzindo um som repetitivo. A psicóloga pede para que ela relaxe e não se incomode com o que ela está fazendo, notando que a ofendida está meio arredia com o procedimento. A psicóloga começa então a fazer algumas perguntas sobre sua trajetória de vida, como conheceu o marido, porque se casaram e como está sendo a sua vida desde que casaram. A ofendida responde a todas as perguntas com muita calma. Ela comenta que se conheceram muito jovens e que sabia desde o primeiro momento em que o viu, que ele seria um grande amor. Em seguida, detalha que sempre teve uma pressão familiar e religiosa pelo casamento, e também esclarece que notou que isso nunca foi a vontade do marido, e que sente que ele nunca gostaria de ter se casado com ela. Neste momento, ainda batendo as mãos nas coxas de Paula, ela comenta algo como:

Você percebe que tem algo morto dentro da sua casa e que precisa enterrar? Lamento te dizer tudo isso, mas seu marido claramente faz tudo isso porque quer se libertar desse casamento que ele nunca quis. E você mais do que ninguém sabe perfeitamente disso. Você precisa o deixar ir, olha o que isso está causando com vocês. Pensa no que pode causar nos filhos de vocês vendo tudo isso entre vocês.

Ela se emociona muito durante todo o processo enquanto a doutora tenta convencê-la de que o marido não a ama a ponto de continuar um casamento saudável. Depois de uma longa e emocionante conversa, ela faz a ofendida entender que o marido pode estar sendo tâo agressivo com ela, porque é a única forma que ele tem de tentar fazê-la enxergar que ele não quer mais esse casamento e está ansioso por uma vida diferente. Mesmo assim, ela só se sente convencida, caso seja estabelecida um pensão provisória para que ela não se sinta tão insegura financeiramente. Todos a asseguram de que seria possível. Preocupados se ela voltaria para casa com ele, perguntam se o seu irmão não poderia buscá-la no fórum e abrigá-la naquela noite, pelo menos até os ânimos se acalmarem. Decidida, ela liga para o irmão ir buscá-la. O atendimento foi transferido para a sala de audiência ao lado, que contava com a presença do juiz, promotor, e dois defensores públicos.

\section{$\mathrm{O}$ atendimento multidisciplinar e a audiência}

Dois aspectos chamam a atenção no caso acima. $\mathrm{O}$ primeiro no que se refere à dinâmica do atendimento a partir da técnica utilizada 
pela psicóloga como primordial para focar novos elementos dos casos. E o segundo, na transformação do atendimento feito pela equipe multidisciplinar em uma audiência ministrada por um juiz e o Ministério Público.

A conversa mais detalhada entre a parte e a psicóloga sobre aspectos que não apresentavam uma ligação direta com o que constava nos autos foi importante para que a equipe pudesse fazer uma leitura diferenciada do caso, e pudesse perceber que os conflitos entre o casal estavam sendo causados graças a uma insatisfação do homem com o relacionamento. Para que se chegasse a essa conclusão, foi pertinente entender aspectos referentes à história do casal e como eles se conheceram, histórico da família com a religiấo, relação com os filhos, com a profissão, além do comportamento do casal um com o outro. $\mathrm{O}$ espaço para que esse conjunto de aspectos aparecesse no diálogo entre as partes e a equipe foi fundamental para que esta iniciasse o esforço juntamente com a parte, de que uma mudança de comportamento dela e a opção pelo fim do relacionamento se configuravam como uma medida mais eficaz para o caso. Enfatizo que tal leitura náo seria possível caso o espaço de enunciação da ofendida fosse reduzido ou não se preocupasse com algo que ultrapassa o limite dos autos do processo. Por essa razão, a técnica e o procedimento utilizado pela equipe foram fundamentais para que viesse a conhecimento de todos que era preciso encontrar medidas legais que fossem capazes de mantê-la em segurança, como o efetivo cumprimento da medida protetiva vigente, além da busca e apreensão da arma.

Durante o atendimento, a equipe demonstra o esforço em deixar claro para a ofendida de que seria possível garantir todas as medidas legais necessárias para que ela e os filhos permanecessem em segurança, tanto física quanto financeira. $\mathrm{O}$ fato da ofendida não trabalhar $\mathrm{e}$ ainda depender economicamente do marido aumentou o medo de ficar desamparada financeiramente e ainda prejudicar a relação dos filhos com o pai. O trabalho da equipe consistiu em demonstrar que suas inseguranças não poderiam deixá-la presa num relacionamento marcado pela violência e pelo desrespeito, e que para isso era cabível estabelecer uma pensão além de determinar quem seria o responsável legal pelos filhos.

Sendo assim, o atendimento se configura como um espaço maior de enunciação das causas originárias do conflito, bem como um espaço que pela ampla atuação de profissionais da psicologia é capaz de demonstrar elementos importantes no desenrolar judicial do processo. $\mathrm{O}$ medo latente da ofendida, tanto das agressóes do marido quando bebe ou do desamparo financeiro, assim como a denúncia da presença da arma em casa e a falta de vontade do marido de continuar com o casamento, contribuíram para que o atendimento fosse transferido para a sala de audiência e orientassem as partes sobre os futuros procedimentos legais sobre o processo.

\section{Os sentidos assumidos pelo atendimento multidisciplinar e consideraçóes finais}

A análise dos atendimentos sugere a configuração de um espaço que permite uma maior elucidação dos sentimentos que o conflito evoca nas partes envolvidas. Em primeiro momento, a caracterização de uma "audiência" para os envolvidos é substituída pela apresentação da equipe multidisciplinar juntamente com o surgimento do termo "atendimento", com a presença de psicólogo em vez de promotor e Juiz.

Apesar dos atendimentos admitirem um caráter judicial, desde a comunicação com as partes, por meio de uma intimação telefônica, 
nos primeiros instantes a equipe esclarece que aquele se caracteriza como um momento em que o ofensor e a ofendida têm para esclarecer todos os motivos que originaram a denúncia, assim como os demais aspectos que está envolvendo o casal, seja entre relaçôes familiares ou financeiras. Mas também esclarecem que a finalidade do atendimento não é substituir uma audiência judicial e sim funcionar como um espaço capaz de identificar a natureza do conflito, em busca de sua completa resolução.

Por diversas vezes, é comum observar a presença de uma postura de caráter mais terapêutico da equipe multidisciplinar, como um espaço aberto para consideraçóes importantes das partes, que podem se configurar como aspectos fundamentais na resolução, ou até mesmo extinção do conflito, e até mesmo ser responsável pelo atendimento ter adquirido um aspecto judicial no mesmo momento, como na apresentação do caso 2 .

O espaço aberto para conversa franca e desassociada de julgamentos de valor ou de moral, é o que permite que os atendimentos se configurem como espaços em que as partes tragam seus medos, anseios, expectativas e emoçóes. A evocação de sentimentos de todos e a exposição de informações até então ocultadas, além de contribuírem para o aspecto terapêutico do atendimento também são capazes de determinar novos rumos de atendimento, gerando inclusive uma mudança de postura na equipe multidisciplinar, no que se refere à necessidade de medidas e atitudes judiciais mais eficazes, e que podem ir além do poder atribuído a função por eles desempenhada. $\mathrm{O}$ que acontece nos casos supracitados indica que a equipe, ao avaliar a gravidade dos casos, julgará que tais precisam de uma intervenção judicial imediata já que, de certa forma, compromete a integridade física, emocional ou psicológica dos envolvidos, seja da mulher, dos filhos, seja dos demais familiares envolvidos.

Destaca-se que tais decisóes da equipe podem ser feitas por critérios diversos, até mesmo aleatórios ou em decisões momentâneas baseadas no "sentir" ou como resultado da experiência de lidar com tais casos parecidos. Mas até o momento, os fatores mais comuns identificados na observação dos atendimentos, como capazes de determinar a mudança de rumo dos atendimentos, seria o consumo de bebidas alcoólicas e/ou drogas, seguidas de um comportamento agressivo, aliada a antecedentes criminais, algum tipo de comportamento violento anterior, ou atitudes suspeitas que possam desencadear reaçóes violentas, como foi possível perceber nesse último caso.

Levando esse aspecto em consideração, a presença do álcool é recorrente como fator determinante do conflito na relação e o seu combate acaba sendo um importante aliado do tratamento iniciado nas salas de atendimentos e continuado através do encaminhamento para tratamento nos alcoólicos anônimos ou atendimento psicossocial

Finalizo este artigo ao apontar que os resultados obtidos sugerem que os atendimentos, apesar de não se caracterizarem como uma audiência preliminar convencional, ao se pensar numa perspectiva comparada com os demais juizados, sem a presença de um juiz, o atendimento desempenha uma função similar no que se refere à decisão da referida acerca do futuro do processo, seja a escolha entre o arquivamento, a suspensão condicional ou prosseguimento do feito.

O material levantado indica que assumem um caráter de audiência preliminar, ao se considerar que o juiz, mesmo presente em outra sala, é ciente da decisão da ofendida e profere imediatamente a decisão anexada ao relatório de atendimento. Além de assumirem características como o sigilo de informaçôes, a intimaçáo das partes para o comparecimento a uma audiência, mesmo que somente ao chegar ao 
fórum as partes tomem conhecimento sobre a natureza dos atendimentos. Ao mesmo tempo, a presença dos psicólogos e assistentes sociais, ao invés dos magistrados, abre um espaço de enunciação mais claro e aberto sobre as situaçôes que envolvem o conflito, funcionando com uma finalidade terapêutica, capaz de trazer à tona diversos elementos capazes de ajudar na resolução do conflito em sua origem.

Apesar de a linha que delimita a finalidade ora terapêutica ora judicial dos atendimentos ser bastante tênue, o atendimento acaba assumindo características próprias de acordo com a gravidade do caso delimitada pelos profissionais membros da equipe. Por essa razão, é totalmente válido pensar na proposta do juizado do Núcleo Bandeirante como uma a proposta aberta para se tratar dos casos de violência doméstica de acordo com as suas necessidades mais urgentes, além de ser uma proposta que tenta implantar medidas que visem à implementação da lei 11.340/06, ao mesmo tempo em que utiliza formas que buscam a resolução efetiva dos conflitos de origem doméstica.

\section{Notas}

1. 1. Este trabalho é resultado de uma pesquisa que teve início na graduação, fruto do Programa de Iniciação Científica da Universidade de Brasília, intitulada "Reparação, Justiça e Violência Doméstica, perspectivas para reflexão e ação - Parte 2", que é continuidade de pesquisa de mesmo título iniciada em 2010.
A pesquisa dialoga diretamente com pesquisas já em curso em outros estados do Brasil, no âmbito do Instituto de Estudos Comparados em Administração Institucional de Conflitos (INCT/ InEAC).

\section{Referências bibliográficas}

AMORIM, Maria Estela. Despenalização e penalização da violência contra a mulher. In: R.SJRJ, Rio de Janeiro, n. 22, p. 111-128, 2008.

AZEVEDO, Rodrigo Ghiringhelli de. Sistema penal e violência de gênero: análise sociojurídica da Lei 11.340/06. In: Soc. Estado. Brasília, v. 23, n. 1. 2008.

CORTIZO, Maria Del Carmen. Judiciarização do privado e violência contra a mulher. In: Rev. Kátal, Florianópolis, v. 13 , n. 1, 2010, p. 102-109.

IZUMINO, Wânia. Delegacias de Defesa da Mulher e Juizados Especiais Criminais: mulheres, violência e acesso à justiça. XXVIII Encontro da Associação Nacional de Pós Graduação em Ciências Sociais - ANPOCS, Caxambu, Minas Gerais, 2004

KANT DE LIMA, Roberto. Sensibilidades jurídicas, saber e poder: bases culturais de alguns aspectos do direito brasileiro em uma perspectiva comparada. Disponível em: <http://www.uff.br/ineac/sites/default/files/02-anuarioantropologico-robertokant.pdf $>$. Acesso em 24 de março de 2012.

MENDES, Regina Lúcia Teixeira. Igualdade a brasileira: cidadania como instituto jurídico no Brasil. Rio de Janeiro: Editora Lumen Juris, 2005.

PASINATO, Wânia. Lei Maria da Penha. Novas abordagens sobre velhas propostas. Onde avançamos? In: Civitas - Revista de Ciências Sociais. Porto Alegre, vol.10, n. 2, p. 216-232, maio/agosto, 2012.

\author{
autora Ranna Mirthes Sousa Correa \\ Graduada em Ciências Sociais / UNB
}

Recebido em 25/11/2013

Aceito para publicação em 16/12/2013 